\title{
SELEÇÃO, CAPACITAÇÃO E FORMAÇÃO DA EQUIPE DE PROFISSIONAIS DOS ABRIGOS: O HIATO ENTRE O PRESCRITO E O REAL
}

\author{
SHELTER PROFESSIONAL SELECTION, CAPACITY BUILDING, AND TRAINING:THE GAP BETWEEN \\ WHAT IS PRESCRIBED AND REALITY
}

SELECCIÓN, CAPACITACIÓN Y FORMACIÓN DEL EQUIPO DE PROFESIONALES DE LOS ABRIGOS: LA BRECHA ENTRE LO PRESCRITO Y LO REAL

\author{
Elizabeth Espindola Halpern ${ }^{1}$ \\ Ligia Maria Costa Leite ${ }^{2}$ \\ Mayara Cristina Muniz Bastos Moraes $^{3}$
}

Resumo Objetivou-se verificar se as percepções da equipe de profissionais dos abrigos para jovens acerca das dificuldades no trabalho estariam relacionadas às deficiências na seleção, capacitação e formação continuada. Foi realizada uma pesquisa qualitativa em dois abrigos localizados na cidade do Rio de Janeiro, entre 2008 a 2010. As 47 entrevistas com profissionais dos abrigos e as observações de campo nas oficinas em grupo foram transcritas. A análise dos dados identificou pontos críticos que podem gerar violências, interferir no manejo das tarefas e agravar os riscos psicossociais, comprometendo a saúde mental dos cuidadores e jovens assistidos. Ao se confrontar seus relatos com as recomendações contidas nas Orientações técnicas para os serviços de acolhimento para crianças $e$ adolescentes, conclui-se que, embora esse documento possibilite mapear as ações dos profissionais e nortear as melhores formas para realizarem a tarefa de acolher, ele precisa ser assimilado e vivenciado para reduzir a distância entre o prescrito e a realidade.

Palavras-chave cuidador; unidades de acolhimento; adolescentes; capacitação profissional; seleção de pessoal.
Abstract This study aimed to determine if the views the staff working at shelters for youth have about the hurdles they face at work are related to deficient selection, capacity building and training. A qualitative survey was carried out at two shelters located in Rio de Janeiro, Brazil, between 2008 and 2010. The 47 interviews conducted with shelter professionals and field observations at group workshops were transcribed. The analysis of the data identified hot spots that can lead to violence, interfere in task management and worsen psychosocial risks, compromising the mental health of both caregivers and of the youth being assisted. Their accounts were compared with the recommendations featured in the Technical Guidelines for foster care for children and adolescents, and we concluded that although this document allows the mapping of the actions to be taken by the professionals and provides guidance on the best ways to accomplish the fostering task, it needs to be assimilated and experienced in order to reduce the gap between what is prescribed and the actual reality.

Keywords caregiver; shelters; adolescents; professional training; personnel selection. 


\section{Introdução}

A história do abrigamento de jovens no Brasil nos últimos séculos pode ser retraçada acompanhando as transformações nas instituições encarregadas de asilar os órfãos e os desvalidos: escolas, asilos, hospitais, orfanatos e albergues. Geralmente, elas estavam alinhadas com o princípio do recolhimento em instituições fechadas, quase sempre internatos-escolas ou internatos-prisões. Apesar das mudanças na percepção sobre o abrigamento desde a criação do Recolhimento de Órfãs e Desvalidas de Santa Thereza, no Rio de Janeiro, a partir de 1740, ainda prevalece a visão de que os jovens deveriam ser objeto de modelagem social (Leite, 2001).

Ao longo dessa trajetória, que acompanhou o processo de formação da nação brasileira, o Estado assumiu a responsabilidade pelo acolhimento, obstando a hegemonia da Igreja Católica e das entidades filantrópicas. Apesar da criação do Estatuto da Criança e do Adolescente (ECA) (Brasil, 1990), que passa a considerá-los sujeitos de direitos, e da Nova Lei da Adoção (Brasil, 2009), que procura esgotar as chances de reinseri-los no ambiente familiar biológico, o Estado ainda atua de forma assistencialista e paternalista.

O tema é intricado e não se esgota com a questão da adoção. Inclusive, nas últimas décadas, muitas pesquisas foram feitas sobre os jovens abrigados, algumas discorrendo sobre a Teoria Bioecológica do Desenvolvimento Humano e a análise do contexto (Bronfenbrenner, 1996; De Antoni e Koller, 2001; Carvalho, 2002; Siqueira e Dell'Aglio, 2006; Rosa et al., 2010; Delgado, 2012; Rosa et al., 2012). Entretanto, este artigo privilegia questões atinentes aos profissionais dessas instituições.

Pesquisadores sinalizam uma melhora na qualidade da assistência dos abrigos (Pasian e Jacquemin, 1999; Arpini, 2003; Martins e Szymanski, 2004), associada à implementação do ECA (Rizzini e Rizzini, 2004), superando a visão de que esses locais seriam prejudiciais aos jovens. A perspectiva do 'desenvolvimento-no-contexto' tem ajudado a compreender a extensão dos fatores protetivos e dos riscos existentes nesses espaços. Porém, aspectos essenciais devem ser considerados para que a equipe de profissionais dos abrigos $^{4}$ possa exercer, minimamente, sua tarefa de cuidar. Silva (2004) assinala a necessidade da profissionalização dos educadores e de uma política de recursos humanos que garanta a capacitação permanente, incentivos, valorização e remuneração condizentes. O impacto direto da formação continuada no desenvolvimento dos abrigados implica investimentos na construção de uma consciência social em favor do seu bem-estar (Bazon e Biasoli-Alves, 2000; Yunes, Miranda e Cuello, 2004), além de produzir efeitos favoráveis nos jovens, minimizando as chances de eles se tornarem "desafiliados sociais" (Castel, 1998). Ações eficazes embasadas nos princípios de reabilitação psicossocial (Pitta, 1996) devem ser dirigidas aos jovens para conseguirem se 
'reafiliar' na estrutura social (Leite et al., 2011). Moraes e colaboradores (2012) sustentam que esses princípios também devem ser levados em conta pela equipe para atenuar os riscos à sua saúde mental, sobretudo pelo despreparo para lidar com os desafios laborativos.

A realidade demonstrada com o Levantamento Nacional de Abrigos para Crianças e Adolescentes identificou cerca de vinte mil jovens vivendo em 589 abrigos (Silva, 2004). Logo, o papel dos profissionais dos abrigos se torna central, principalmente considerando os efeitos da experiência do abrigamento nesses jovens.

\section{Objetivo, método e análise dos dados}

Este trabalho apresenta parte dos resultados da pesquisa "Violência, Juventude e Saúde Mental", realizada no Instituto de Psiquiatria da Universidade Federal do Rio de Janeiro (IPUB/UFRJ), de 2008 a 2010, visando a estudar a saúde mental dos cuidadores e jovens abrigados nas unidades de acolhimento municipais (Leite et al., 2008).

O objetivo deste artigo foi verificar se as percepções dos profissionais dos abrigos acerca das dificuldades no trabalho estariam relacionadas às deficiências na seleção, capacitação e formação continuada.

Entrevistas semidirigidas foram feitas com 47 profissionais e observações participantes ocorreram em um centro de acolhimento (CA) e em uma casa de passagem (CP) na cidade do Rio de Janeiro, estimulando-os a contarem livremente suas histórias pessoais e profissionais (Groleau, Young e Kirmayer, 2006). Assim, surgiram dados relativos ao relacionamento desses trabalhadores com a instituição, os colegas, os jovens abrigados e outras unidades das redes. Empregou-se o método da história oral (Alberti, 2004), por captar um conjunto de aspectos que espelham a riqueza da vida social de um grupo, permitindo que o entrevistado pudesse (re)significar suas vivências.

Embora tenham sido transcritas as 47 entrevistas, somente 17 foram examinadas por serem atinentes ao tema deste artigo. Devido à extensão do material colhido e à variedade de tópicos abordados nas entrevistas, foram analisadas as que fizeram referência às questões laborativas, realizadas com seis educadores sociais e duas assistentes sociais do CA, e sete educadores sociais, um assistente social e um psicólogo da CP.

Algumas questões nortearam a construção e as análises dos dados coletados, para apreender os aspectos subjetivos de cada entrevistado sobre a forma como lidava com sua própria condição profissional, a saber: a escolha da ocupação; as representações do seu cotidiano de trabalho; a formação e capacitação para o desempenho das tarefas; o trabalho em equipe; os impasses e tensões laborais; a realização e o reconhecimento profissional, entre outros. 
As observações de campo ocorreram durante as oficinas em grupo, cujos temas podiam ser previamente definidos ou não, para conhecer a dinâmica das relações dentro dos abrigos e favorecer um espaço de reflexão sobre os pontos de tensão. Os dados foram registrados em relatórios e cadernos de campo para análise posterior (Minayo, 2006; Minayo, Deslandes e Gomes, 2007).

Embasada na Teoria da Comunicação (Boudon, 1998), a análise das entrevistas foi feita por meio da abdução que identificou alguns pontos críticos capazes de gerar violências, interferir na condução das práticas e contribuir para o agravamento de riscos psicossociais, comprometendo a saúde mental dos profissionais e dos jovens. Este artigo se desenvolveu a partir do exame de um desses pontos e analisou as possíveis (in)coerências com as diretrizes do documento Orientações técnicas para os serviços de acolhimento para crianças e adolescentes 5 (Conanda/CNAS, 2008), em especial quanto à seleção, capacitação e formação continuada dos cuidadores. Para tal, foram examinados os registros colhidos nas observações de campo e nas transcrições das entrevistas.

Cabe esclarecer que houve uma limitação da investigação, especialmente porque o material que serviu de fonte para este estudo foi construído e compilado a partir de 2008, por antigos integrantes da pesquisa (Leite et al., 2008). Os dados demográficos encontrados nos cadernos de campo ativeram-se ao local de trabalho (CP ou CA) e à função desempenhada (educador social, assistente social e psicólogo). Embora a inclusão de dados como idade, gênero ou tempo de serviço pudesse enriquecer a análise dos dados, espera-se que o conteúdo de suas falas seja eloquente e esclarecedor para esta discussão, e que as informações encontradas e suas análises aprofundem a reflexão sobre a situação dos profissionais nas instituições de acolhimento.

Foram adotados nomes fictícios para preservar as identidades dos participantes. Ademais, os nomes do CA e da CP foram omitidos para proteger a confidencialidade das informações dos profissionais. Todos os participantes assinaram o termo de consentimento livre e esclarecido. A pesquisa foi aprovada pelo Conselho de Ética em Pesquisa do IPUB/UFRJ e pela Comissão Nacional de Ética em Pesquisa (Conep) em 2006, processo n. 0008.0.249.000-06.

\section{Contexto}

Ainda que o CA e a CP façam parte da microrrede de assistência social no município do Rio de Janeiro e pertençam à mesma rede acolhedora da Secretaria Municipal de Assistência Social (SMAS), há traços e especificidades que os distinguem. 
O CA acolhe adolescentes entre 14 e 17 anos e 11 meses que ainda não estão prontos para serem reinseridos na sociedade. Embora o acolhimento institucional deva ser uma medida de proteção provisória e excepcional (Brasil, 1990), espera-se que eles permaneçam o tempo necessário para gerenciarem suas vidas, construindo uma 'porta de saída', econômica e emocional, por meio da 'reafiliação' (Leite et al., 2011). Segundo Saraceno (1999), trata-se de um processo de reconstrução, ou melhor, de reabilitação psicossocial.

A CP se propõe a ser uma moradia provisória para os adolescentes entre 13 a 17 anos e 11 meses que enfrentam situações de risco social, com prazo de permanência de trinta dias. Caso o jovem não esteja pronto para a convivência em um CA, nem para voltar à sua família, o prazo poderá ser prorrogado por mais 15 dias. A CP tem por objetivo reduzir a distância entre o desejo manifestado pelo jovem de deixar a situação de rua e a dificuldade de aceitar a rotina de compromissos e responsabilidades exigida pelo acolhimento.

\section{Resultados}

Os resultados a seguir ajudam a compreender o possível hiato entre o que está previsto no documento de orientações técnicas e no ECA e a realidade.

Conforme explicado anteriormente, os entrevistados eram assistentes sociais, psicólogos e educadores sociais. Estes últimos subdivididos em duas categorias: agentes comunitários da prefeitura, com vínculo de servidores municipais, e educadores sociais, terceirizados e selecionados por organizações não governamentais (ONGs) conveniadas com o município.

\section{Objetivos dos abrigos}

Com a promulgação do ECA foi possível iniciar o rompimento da enraizada 'cultura da institucionalização'. Desde então, colocou-se em marcha uma reversão da lógica do abrigamento que impregnava o discurso e as práticas desde a colonização brasileira (Conanda/CNAS, 2008), sobretudo procurando garantir a permanência excepcional e provisória dos jovens nos abrigos, com condições materiais de habitabilidade, alimentação, higiene e vestuário para ele poder viver e conviver, assim como os direitos ao lazer, educação, saúde, convivência comunitária, cultura, apoio social e psicológico (Brasil, 1990).

Pesquisadores têm investigado os efeitos do ambiente institucional dos abrigos nesses indivíduos, inclusive com a abordagem ecológica de Bronfenbrenner (1996), por reconhecer os processos evolutivos e os múltiplos fatores que influenciam o desenvolvimento humano. Carvalho (2002) sinalizou que 
o ambiente institucional não seria o melhor espaço para o desenvolvimento dos jovens abrigados, devido ao atendimento padronizado, alto índice de crianças por cuidador e falta de atividades planejadas. Entretanto, outros estudos revelaram que perante as adversidades vividas por essas famílias, o acolhimento institucional se torna a melhor solução (Dell' Aglio, 2000).

A despeito dos debates profícuos sobre o tema na atualidade, constatou-se que muitos entrevistados desconheciam a própria missão da instituição:

Até hoje, eu vou falar, eu não entendi esse 'lance' de abrigo! Porque eu pensava que abrigo fosse pra quem não tivesse família, porque a família tivesse algum problema de bebida, sei lá, batesse neles. Então, eu vi que abrigo não é isso. No abrigo, é o adolescente envolvido com 'boca de fumo' (Educador social 1 da $\mathrm{CP}$ ).

Considerando que os cuidadores são os profissionais que têm maior contato com os jovens, não só em termos de carga horária, como também em função do estreito convívio cotidiano, é inconcebível que eles não tenham plena ciência do papel dos abrigos e de suas atribuições.

\section{O papel e a valorização dos cuidadores}

O documento com as orientações é bastante claro em relação ao papel do cuidador no fortalecimento de laços familiares e a sua importância para o êxito do processo de reintegração familiar ou encaminhamento para família substituta. Para que o profissional cumpra bem o seu papel, ele deve

vincular-se afetivamente às crianças/adolescentes atendidos e contribuir para a construção de um ambiente familiar, evitando, porém, 'apossar-se' da criança ou do adolescente, competir ou desvalorizar a família de origem ou substituta (Conanda/CNAS, 2008, p. 13).

Entretanto, muitos dos profissionais não estão seguros de suas funções: “É, nós estamos tentando ver. É reeducar os meninos pra reintegrá-los à sociedade. Eu acho que é isso!" (Educador social 1 do CA). Muitos deles tendem a sobrepor o papel de educador social ao de progenitor:

Eu levava sempre um [menino] no fim de semana pra passar comigo lá em casa. Natal, Carnaval. E não era sempre os mesmos, não! (Educador social 5 da $\mathrm{CP}$ ).

Então a gente tem que tratar eles como se fossem filhos nossos. A gente quer para eles o que quer pros nossos filhos: o melhor! É, de certa forma, tenho um papel de mãe" (Psicólogo 1 da CP). 
O nosso objetivo é ajudar os meninos o máximo possível. Devido à circunstância que tem na vida deles, a gente procura ser uma família. Porque nós somos uma grande família de filhos e irmãos. Esse é o papel do educador: como se fosse um pai e a mãe. Pai e mãe! (Assistente social 1 do CA).

Essa 'mistura' sugere que as fronteiras entre o espaço do trabalho e o privado são virtuais, sobretudo quando envolvem relações sociais e questões de saúde. Bottega e Merlo (2010, p. 260) reiteram que: “já que não é possível separar nossa vida na família, em casa, da vida no trabalho, nos seus diversos locais. Gradativamente esses ambientes se misturam, se confundem, tornando a separação ainda mais complicada".

\section{Seleção, capacitação e acompanhamento dos profissionais}

\section{Seleção}

O manual sobre orientações técnicas adverte que o processo seletivo dos educadores sociais deve ser criterioso, para assegurar a contratação de pessoal qualificado e com perfil alinhado às suas funções. Para tal, é necessário fazer uma ampla divulgação, difundindo informações claras sobre o serviço no abrigo, perfil dos usuários, atribuições e exigências, salário e carga horária. Todavia, a escolha dos educadores não costuma ser fruto de um processo seletivo: "Ele vem encaminhado. As direções não têm mais essa autonomia, não participam mais desse processo seletivo. 'Eu preciso de um educador'. 'Tem um aqui!' 'Serve' [reproduzindo um diálogo]" (Assistente social 1 da $\mathrm{CP}$ ). As circunstâncias parecem ditar a forma como a tarefa será exercida:

Em 2004, eu fiz um estágio, ficava observando e ela [diretora] me chamou pra trabalhar: 'Você quer? Sabe como é que é?' Porque não é um trabalho fácil mexer com adolescente. Até com os nossos filhos já é difícil! Imagine esses! Eu precisava mesmo, tava desempregado! Aí, aceitei (Educador social 2 do CA).

Além de não haver uma seleção criteriosa para o cargo, um dos educadores atestou o despreparo para lidar com a fase da adolescência, período que requer um manejo mais específico:

Na verdade, eu trabalhava como agente de portaria no outro Cemasi, ${ }^{6}$ e lá eu tive a oportunidade de passar pra educador social. Meio que um porteiro, recepcionista, fazer de tudo um pouquinho desses dois. E aproveitei a oportunidade 
pra trabalhar como educador. Eu tomei até um susto, um dia, porque eu achava os adolescentes muito difícil (sic) de lidar (Educador social 3 do CA).

A seleção para integrar a equipe técnica não costuma contemplar o critério de formação e interesses profissional e pessoal:

Bom, no caso, a única razão que eu tive é porque era perto da minha casa. Por isso que eu escolhi (Educador social 2 da $\mathrm{CP}$ ).

Não tive nenhuma motivação especial. Fui lotada numa unidade que tinha esse trabalho pra ser realizado. Não foi uma escolha, foi o trabalho que me apresentaram. Era a carência do momento. Fui desenvolvendo o trabalho e fui gostando dele (Educador social 4 do CA).

Conforme os relatos, os profissionais concursados para o serviço público são alocados nos CAs sem que os gestores analisem, minimamente, o seu histórico profissional:

Pra mim, esse é o maior equívoco da Secretaria. Eu não tive formação nenhuma. Não quiseram saber de meu currículo, onde é que eu estava, para onde é que eu fui; me joga lá e se vira (Educador social 5 do CA).

Eu não consigo nem te explicar. Eu acho que nós trabalhamos porque nós precisamos. Aceitamos o trabalho porque precisamos. Se não fosse isso, a gente procurava outro serviço melhor, que a gente possa fazer também (Educador social 3 da $\mathrm{CP}$ ).

Tinha profissional aqui que sempre trabalhou na saúde, amava a saúde, não queria trabalhar com adolescente. Fica mais difícil quando você não tem uma predisposição pra trabalhar com aquilo; você só fica pensando em se transferir (Psicólogo 1 da CP).

Dentre algumas das características pessoais desejáveis, segundo o documento de orientações técnicas constam: aptidão para o cuidado com crianças e adolescentes; habilidade para trabalhar em grupo; e a capacidade de mediação de conflitos - importantes para o desempenho da tarefa de educador social. Um entrevistado relatou como ocorreu sua contratação:

Eu nunca tinha trabalhado com adolescente de rua. Aí, uma moça que trabalha na rede falou: 'Eu vou botar você pra trabalhar comigo, já tá tudo certo!' Aí, eu falei: 'O que é isso de já tá tudo certo? Me explica isso? Qual é o serviço?' ‘Educador social' [respondeu]. Ela me passou o que é o educador social, eu fiz um tipo de curso. Fui trabalhar na Casa-lar, peguei a casa cheia, quase trinta, eram três 
educadores. No início foi meio complicado: 'Eu vou chutar o balde, não dá, isso não é pra mim!' Então, eu fui ficando (Educador social 4 da CP).

\section{Capacitação/Capacitação Introdutória}

Na publicação Orientações técnicas para os serviços de acolhimento para crianças e adolescentes são enfatizadas a relevância do investimento na capacitação inicial e a formação continuada (Conanda/CNAS, 2008). A capacitação introdutória engloba:

Apresentação do projeto político pedagógico da instituição; integração à equipe; acompanhamento como observador dos diferentes momentos da rotina institucional e posterior discussão sobre as observações. O nível de experiência do(a) cuidador(a)/educadora(a) norteará o repasse e o conteúdo das informações neste momento de adaptação à rotina da instituição (Conanda/CNAS, 2008, p. 26).

Entretanto, outro entrevistado contou como ocorreu sua contratação e capacitação:

Foi a oportunidade que apareceu primeiro. Por causa de um amigo meu que é educador. Ele comentou comigo que tava precisando de um pessoal aqui. Aí, como eu estava parado, meu amigo me explicou tudo certinho (Educador social 6 do CA).

A capacitação introdutória ocorreu com a convivência com os jovens, como informaram os próximos educadores sociais:

Eles [jovens] tão me formando. Porque eu, na verdade, não tenho nenhuma formação, não sou capacitado em nada nessa área. Eu tô me tornando capaz hoje. Mas eu não tive nenhuma prática nessa área (Educador social 3 do $\mathrm{CA}$ ).

$\mathrm{Na}$ época que entrei, foi uma época que faltava muito funcionário. Tava uma defasagem. Não havia tempo [para capacitar]. Era entrar e trabalhar: vendo e fazendo (Educador social 5 da $\mathrm{CP}$ ).

Os profissionais deveriam estar familiarizados com as etapas do desenvolvimento da criança e do adolescente, as peculiaridades, desafios e comportamentos típicos dos jovens, especialmente dos que são vítimas de abandonos e de diversas formas de violência. Ademais, eles deveriam ser informados sobre o Sistema Único de Assistência Social, o Plano Nacional de Convivência Familiar Comunitária e o ECA: 
Eu trabalho há muito tempo como educador e já há muito tempo que você não tem uma capacitação, nem reunião, nem curso, não discute nada. Quem tá novo na rede, não sabe nem o que é o ECA direito. Aí, enfim, não dá pra você fazer um trabalho desse jeito se os caras não sabem o que eles tão fazendo aqui. Qual o papel deles dentro desse negócio. Você não tem um trabalho desses, nem pros adolescentes, nenhum preparo (Educador social 2 do CA).

\section{Capacitação/Capacitação Introdutória}

O manual de orientações recomenda que determinados cuidados sejam tomados para uma correta capacitação prática do educador social:

Antes de assumir suas funções, o/a cuidador/educador deverá passar por um período mínimo de 80 horas acompanhando, como auxiliar, os diferentes momentos da rotina institucional, sempre sob supervisão de um(a) cuidador/educador experiente e da equipe técnica (Conanda/CNAS, 2008, p. 26).

A capacitação pode, entretanto, acabar ocorrendo na prática cotidiana. A realidade dos abrigos requer uma formação maior do que a oferecida em cursos de conteúdo genérico, pois eles não dão conta dos desafios que esses jovens impõem aos profissionais. Apesar da capacitação para essa tarefa ocorrer no embate cotidiano, é preciso que o neófito fique sob a supervisão de um profissional experiente. Em relação ao tipo de treinamento recebido, os entrevistados assim se manifestaram:

A capacitação foi no dia a dia (Assistente social 1 da CA).

Na verdade a gente só aprende aqui dentro, só atuando mesmo. Eu gostaria muito. Não tenho nenhuma experiência. Eu sei que tenho que ser trabalhada; com a experiência do dia a dia eu vou pegando esse pique pra lidar com eles (Educador social 1 do CA).

Você pode fazer quinhentos cursos, mas na prática é totalmente diferente. Tem gente que nem completa um dia. Chega de manhã, aquela empolgação, bota a blusa, fica aí e, antes de meio-dia, 'quero ir embora' (Educador social 6 da CP).

\section{Formação continuada}

A formação continuada é outra etapa importante para o êxito do trabalho no abrigo: 
Depois da contratação, para adaptação à rotina institucional é fundamental o acompanhamento sistemático do profissional, incrementado com capacitações continuadas. A rotina de uma instituição de acolhimento não é fácil. São várias crianças, por menor que seja o grupo, com diferentes perfis, necessidades e urgências (Conanda/CNAS, 2008, p. 27).

O documento do Conanda/CNS aconselha: reuniões de equipe periódicas para a discussão de casos; formação continuada sobre temas recorrentes do cotidiano; estudos de caso; supervisão institucional com profissional externo; encontros diários de 15 a vinte minutos entre os profissionais dos diferentes turnos para troca de informações; grupo de escuta mútua; espaço de escuta individual; avaliação, orientação e apoio periódicos pela equipe técnica.

Quanto às reuniões periódicas, as narrativas indicaram que a equipe se reúne eventualmente: “É difícil parar um pouco com aquele movimento ali que engole a gente; parar pra poder estudar um pouco o caso e ver o que tá envolvido. Não há um espaço permanente, não tem espaço definido" (Psicólogo 1 da $\mathrm{CP}$ ).

As supervisões e reuniões ocorriam regularmente no CA até 2008. A partir de 2009, passaram para um segundo plano devido à emergência de vários fatores: mudança de prédio, realização de pequenas obras e a execução de obrigações burocráticas consideradas pela equipe técnica como prioritárias. Assim, deixou-se de proporcionar um espaço para a promoção da saúde mental dos próprios funcionários, deixando-os mais vulneráveis ao desgaste mental. Dejours (1999, p. 171) confirma que "o sofrimento está sempre ligado à degradação das condições de discussão e de intercompreensão".

Os profissionais expressaram, assim, a falta que sentem desse tipo de encontros:

Pra te dizer a verdade, teve reunião ano passado [2008]. Não me lembro nem quando, às vezes tem, vai ter agora (Assistente social 2 do $\mathrm{CA}$ ).

Muito importante ter, ajuda você a certas atitudes, a repensar certas coisas. É de reflexão, o estudo do que é ser educador social, de qual atitude você deve tomar (Educador social 7 da $\mathrm{CP}$ ).

Isso é uma coisa que eu acho que tinha que ter. Falta, falta (Educador social 5 da $\mathrm{CP}$ ).

Não tem que ser só educador, tem que ser todo mundo. As equipes, da cozinha, não entendem muito o trabalho nosso [dos técnicos]; eles não têm esse entendimento. Às vezes, um menino retorna pra cá: 'Ah, por que ele voltou? Ah, por que 
ele ainda tá aqui?' Então, essas reuniões são importantes pra que eles possam entender esse fluxo. Eu, quando posso, converso com eles (Assistente social 1 da $\mathrm{CP}$ ).

Reuniões com todos os profissionais promoveriam a coesão, enriquecendo o trabalho com a troca de saberes e valorizando os recursos pessoais e profissionais dos envolvidos:

Eu acho que ainda existe uma grande divisão da equipe da frente [técnicos] e a equipe aqui de trás [educadores]. Eu acho que deveria ser uma equipe só, cada um com seu papel. (...) Então, assim, o trabalho seria muito mais rico se trocasse isso aí, sabe? Se houvesse uma troca, eu acho que os técnicos poderiam ajudar muito os educadores. Porque, quando você soma os conhecimentos, você constrói um conhecimento muito maior. Tem toda aquela parte teórica e tudo mais. O educador tá mais na prática (Educador social 4 da $\mathrm{CP}$ ).

A realização de reuniões transcende o mero formalismo a ser cumprido na agenda semanal/mensal. A superação dos problemas e a promoção da saúde integral nos abrigos podem ser obtidas com a criação dos espaços de fala e de escuta do trabalhador. Na ausência de reuniões regulares, os profissionais tendem a buscar suporte nas conversas informais. Embora esses bate-papos sejam úteis e minimizem a ansiedade e o desgaste decorrentes dos desafios enfrentados nos abrigos, muitas vezes são limitados, não oferecem um suporte com a orientação de um profissional habilitado.

A gente tenta construir um conhecimento coletivo a partir da experiência, mas eu acho isso uma irresponsabilidade. Porque não dá para ficar apostando o tempo todo se vai dar certo ou não (Assistente social 1 do CA).

Mas, é no dia a dia mesmo, com a conversa com as colegas que a gente troca muita coisa. Poder dividir isso, dá um alívio, um apaziguamento, sabe? (Educador social 1 da $\mathrm{CP})$.

No almoço, temos nosso horário de descanso. Ali, nós 'tricota', desabafa (sic), é o nosso momento. A gente senta, conversa e dá opinião. Fala sobre o jovem que foi pra rua de novo, que ficou preso (Educador social 3 da $\mathrm{CP}$ ).

Com efeito, o cuidador acaba contando com seus recursos pessoais para desempenhar o seu trabalho. É possível imaginar o esforço para dar conta da tarefa, ainda mais considerando a complexidade do público assistido e a precariedade da rede de assistência. O documento sobre orientações também aborda o fato de os profissionais ficarem, de algum modo, emocionalmente afetados, como se observa a seguir: 
No começo foi muito difícil. Eu telefonava muito pra uma colega de trabalho, porque ela é uma pessoa informada. Ela sempre trabalhou com criança, ela é uma pessoa da Igreja. Então, ela me dá muito conselho: ‘Você não pode se deixar viver a vida dos outros. Você não pode ficar com pena, não pode usar o sentimento no seu trabalho. Você tem que botar o sentimento de lado. Porque a gente, quando vive a vida dos outros, a gente não vive, a gente vegeta. Então, você tem que aprender isso'. Agora acho que me sinto melhor no trabalho, até porque eu mesmo cheguei a uma conclusão, que meus problemas não eram iguais aos deles, eu não podia continuar assim, eu tenho que trabalhar, eu tenho uma família (Assistente social 1 do CA).

As experiências nos abrigos podem provocar a eclosão de sensações e desejos nos educadores, movidos mais pela emoção do que pela razão. Embora nem sempre seja fácil demarcar uma fronteira entre as experiências da vida privada e profissional, é preciso que eles sejam auxiliados a ter um distanciamento mínimo na relação com os jovens para suportar as angústias e frustrações naturais que emergem desse relacionamento. Como prescreve o manual sobre orientações técnicas,

Para que os cuidadores/educadores consigam cumprir sua função, é necessário que disponham, ainda, de apoio e orientação por parte da equipe técnica do abrigo, bem como de espaço para trocas, nos quais possam compartilhar entre si experiências e angústias decorrentes da atuação, buscando a construção coletiva de estratégias para o enfrentamento de desafios (Conanda/CNAS, 2008, p. 14).

\section{Condições de trabalho adversas}

As narrativas denunciaram a existência da sobrecarga de trabalho:

Aqui é uma 'panela de pressão', pode estourar a qualquer momento. Tá tudo bem, mas, daqui a pouco, você vira as costas e já é uma briga. Já tentaram fazer rebeliões, queimar colchão, trepar em cima do telhado" (Educador social 2 da CP).

Adicionalmente, muitos se queixaram da defasagem no número de cuidadores, assim como da questão salarial:

São vinte na casa e dois educadores? É muito pouco! Tem dia que saio daqui com as minhas pernas doendo, porque não dá pra ficar sentada dez minutos (Educador social 2 do $\mathrm{CA}$ ).

Eu acho que eu aumentaria o número pra reorganizar o trabalho, pra deixar as pessoas menos cansadas, porque se você fica muito irritado, seu discernimento fica comprometido, não vai ser amável (Educador social 4 do CA). 
A maior dificuldade é a questão do salário. Eu acho que, pra gente poder trabalhar bem, a gente tem que ser remunerado da forma que merecemos. A gente fica três meses sem receber (Educador social 6 do CA).

Um cenário de desvalorização do trabalho de educador tende a prevalecer, incluindo a falta do adicional de insalubridade, periculosidade e de assistência à saúde:

Eu não mudaria de função no abrigo, eu arrumaria outro emprego! Não pelo trabalho, mas pelo salário. Eles teriam que olhar bem pra gente e dar um pouco de valor. Mas botam um chefe de família com salário defasado. Eu tenho filho de nove anos, posso tá saindo daqui e levar uma doença que eu peguei aqui dentro pra uma criança inocente que não tem nada a ver com meu trabalho. Mas, se a gente tem um plano de saúde, você trabalha até mais despreocupado. A gente fica pra ganhar 540 reais [valor de 2011] e já estamos com dois meses de salário atrasado! E não tem previsão de pagamento (Educador social 7 da $\mathrm{CP}$ ).

O que falta aqui é o reconhecimento do educador. O educador, eu acho que é o resto do resto pra Prefeitura. Como é que é o nosso salário, 400 e poucos reais [valor de 2011]... Outra coisa, também, que a gente não tem, é periculosidade ou insalubridade. O funcionário da Prefeitura tem, o efetivo. O educador não tem. Aí, você pega um adolescente aqui com tuberculose, com HIV. Tô falando no geral, não tô falando só daqui, não. Você pega adolescente com pneumonia, com sarna, com lepra (Educador social 3 da $\mathrm{CP}$ ).

As condições adversas de trabalho costumam repelir os profissionais mais habilitados. Contudo, embora alguns entrevistados tenham afirmado que a razão inicial para permanecerem era predominantemente de ordem financeira, já que visavam a seu sustento, com o tempo, a motivação maior tornou-se a solidariedade perante a causa do acolhimento. Tal experiência de ordem mais humanitária parece acentuar o envolvimento pessoal dos educadores com os jovens. Consequentemente, as fronteiras entre as realidades pessoal e profissional tendem a se afrouxar. Em geral, os cuidadores não parecem preparados para manejar as emoções despertadas com o contato estreito com os dramas dos jovens, ainda mais sem uma formação adequada e supervisão competente. Muitos tendem a compensar a ausência de capacitação com seus atributos pessoais:

Acho que essa relação fica um pouco até de pai pra filho. Não dá pra ser pai de todo mundo aqui, só quando eu vou dar bronca neles. Eu acho que é isso, essa relação é amizade (Educador social 6 do CA). 


\begin{abstract}
A gente tem eles como filhos, por mais que, às vezes, tem algum que irrita. A maioria tem idade para ser meus irmãos. A gente adquire mesmo aquele carinho, aquele afeto... É aquela questão da preocupação. Eu sou aquele educador que, às vezes, eu chego em casa e, quando posso, eu ligo. 'E aí, como é que tá o serviço? Como é que tá a situação?' Eu sou dessas pessoas que, se a gente pode ajudar, por mais que não vá ser recompensado com dinheiro; a gente tem uma recompensa que não tem explicação. Eu sei que eu tô ganhando algo muito bom, mas, enfim, não sei o que é (Educador social 4 do CA).
\end{abstract}

\title{
Discussão
}

Os desafios laborais enfrentados pelos trabalhadores dos abrigos foram um dos temas mais presentes na pesquisa de Leite e colaboradores (2008), sugerindo a existência de uma lacuna entre o que está prescrito no manual sobre orientações técnicas e a experiência real dos entrevistados. A análise das narrativas revelou que podem existir dificuldades que não são superadas com a simples leitura e aplicação do 'manual'. Apesar da ênfase dada no decorrer deste artigo à necessidade de trazer as normas para o plano da realidade objetiva, a fim de minimizar a improvisação e, assim, reduzir o estresse e o desgaste profissional, vale ressaltar a importância do comprometimento, ou seja, de um tipo de obrigação íntima movida pela ética, tal como é explanado por Costa (2010):

Ética é a relação com um outro singular que sempre exige adendos aos códigos racionais ou espirituais de orientação de condutas. O outro, em sua irrepetível originalidade, pede uma resposta "visceral" às suas interpelações e não a consulta burocrática ao manual da lei instituída, por mais abrangente ou indulgente que seja. O confronto permanente entre as vísceras e o código estaria, assim, na base das queixas atuais sobre a falta de sentido (Costa, 2010, p. 22).

O comprometimento com o outro é aquele que se abastece de uma fonte interna, sobrepujando as soluções livrescas sob medida. Trata-se de uma postura, de uma atitude e de um olhar que só se materializam em gestos quando há empatia. Há que se empreender uma interpretação mais acurada sobre o significado de certos comportamentos desses profissionais, examinando em que medida eles são movidos pela ética da compassividade ou pela dificuldade de perceber os limites e as possibilidades sobre o seu papel.

Inspirando-se nessa dimensão ética, as recomendações prescritas deveriam ser mais do que uma letra estática; seus conteúdos precisariam ser transformados em palavras vivas, aplicadas e discutidas dinamicamente, transportando-as das páginas impassíveis dos livros para o calor da vida, 
emergindo do debate e da interlocução entre os atores envolvidos. Por mais que as orientações contidas no manual aqui citado sejam precisas e válidas, se elas não saírem do papel, nenhum avanço substancial ocorrerá.

O significado da proposta do acolhimento precisa estar nítido na mentalidade de todos os envolvidos nesta empreitada. Indaga-se em que medida os objetivos eminentemente disciplinares, de contenção e controle, prevalecem camuflados no emaranhado das demandas administrativas diárias nas quais esses jovens se convertem em números para a construção de estatísticas, relatórios e planilhas. Diferentes óbices se interpõem, perversamente, entre o profissional e o jovem, obstruindo a consecução da missão do acolhimento. $\mathrm{O}$ atraso no pagamento dos salários, a sobrecarga de trabalho e o corte de funcionários são alguns dos ingredientes que desgastam o indivíduo, mecanizando sua atuação, produzindo um efeito robótico que o deixa menos sensível ao encontro substancial com o jovem. Com efeito, o jovem deixa de ser a figura central e o acolhimento fica a serviço da maquiagem urbana, retirando das ruas suas rugas, suas excrescências e feiura.

A fim de superar os ranços ancestrais, ainda alinhados com a prática do disciplinamento arraigados nas atitudes de alguns profissionais das redes e na operacionalização do recolhimento travestido de acolhimento, é preciso reconhecer a existência desta situação. A atitude de recolher ainda suplanta a de acolher, enquadrando, disciplinando, formatando, domesticando corpos e almas (Foucault, 2007; 1979). O abismo entre as pessoas nos abrigos se adensa com as rotinas, com as metas burocráticas a cumprir e relatórios a redigir, interpondo-se entre o eu e o outro, alimentando o desencontro e sacramentando o reprisado abandono.

O jovem é recolhido à cama, ao banho, à escola, ao estágio, às refeições; ele não é acolhido quando fala, grita e chora. Suas mensagens não são captadas nem decodificadas, mas censuradas para que ele se adapte ao regime alienígena de uma instituição ainda comprometida com o clamor da sociedade por sossego, prometendo-lhe sua reforma, sua reeducação e sua habilitação para o trabalho. Acolher não se resume a pôr o indivíduo portas à dentro, retirando-o das ruas. Recolher é fácil. Acolher requer uma atitude receptiva, o reconhecimento do próximo como um sujeito que tem direito à voz. Para acolher é essencial levar em conta o ponto de vista do outro (Costa, 2010), pois o acolhimento só se faz mediante o encontro. A tarefa de acolher não se restringe às linhas bem redigidas, às palavras bem compostas, seguindo à risca o bulário das orientações técnicas para serviços que acolhem crianças e adolescentes. Estas devem servir de inspiração, mas não garantem a ação. Sobretudo, o acolhimento se consolida quando o jovem existe perante o olhar do cuidador, como protagonista verdadeiro, seu objetivo primeiro.

Não se trata de selecionar, capacitar ou formar porque está escrito e prescrito. $\mathrm{O}$ acolhimento só pode ser feito em nome da ética que dá um sentido 
à vida (Costa, 2010), sob pena de ficar condenado ao individualismo exacerbado que obstrui a formação de vínculos (Bottega e Merlo, 2010); a aplicação da ética dá suporte à tomada de decisões morais e de atitudes, reavendo a dimensão do sagrado (Costa, 2010). Salvaguardar o sagrado: essa é a diferença fundamental, o elo que faltava, a peça da engrenagem que põe em marcha as recomendações do manual citado, tornando-as vivas, animando-as.

A experiência do sagrado permite ao sujeito transcender, livrando-o da obediência mecânica às regras; impulsiona-o a investir, amorosamente, no próximo, arriscando novos caminhos, criando soluções inéditas, incentivando-o a confiar em seu mapa visceral, a orientar-se por sua bússola cardíaca. As respostas surgem no tato, no contato, legitimando a existência do outro, ratificando os seus limites e viabilizando suas possibilidades. Transforma-se em antídoto para superar o silêncio, o esvaziamento moral, social, cultural ou político: o descomprometimento; em contrapartida, a cooperação, a ação conjunta, permite criar um espaço para a fala e para a escuta (Sennet, 2003; Dejours, 2005; Bottega e Merlo, 2010).

Em oposição, a carência de sentido esvazia as chances de contato e deixa um vácuo preenchível pelas papeladas mecanizadas. No cotidiano, profissionais autômatos, desprovidos de uma existência de sentido, agarram-se às fórmulas conhecidas, ao invés de se arriscarem por caminhos insólitos e criativos. São indivíduos reprodutores, em vez de (pro)criadores: repetem, não criam. O encontro genuíno é acionado em favor da geração de vida, da procriação, da atitude que viabiliza a subjetivação do indivíduo, do ser e do viver, contrapondo-se à impermanência dos objetos típica da vida "líquido-moderna" onde prevalece a "superfluidade" (Bauman, 2001).

A reversão desse cenário cinzento exige refletir sobre os processos tradicionais de recrutamento, seleção e treinamento do educador que se limitam ao aparelhamento de profissionais 'válidos' para o mercado. Contudo, a supremacia do modelo disciplinar ainda tem proeminência na formação profissional. Embrutecidos, muitos tendem a se resguardar das angústias e frustrações despertadas nos abrigos, refugiando-se no cumprimento das tarefas que superabundam na jornada de trabalho prolongada. A execução das múltiplas atribuições, em prazos exíguos, impulsiona os trabalhadores a copiarem modelos centenários de educação comprometidos com a formatação. Este é o caminho mais fácil, conhecido, automático, cuja matriz se replica no interior das "instituições totais", onde se procede a uma espécie de "mutilação do eu" (Goffman, 1992). A proposição de um novo desenho institucional ameaçaria as posições estabelecidas e culturalmente consagradas. Uma revisão desse modelo exigiria a flexibilização hierárquica, a reversão nos poderes, nos saberes e nos lugares.

A realização de uma alteração tão profunda nessa engrenagem algo perversa, que se move em nome do controle, é uma meta de difícil reversão, so- 
bretudo porque as próprias relações sociais e profissionais são impregnadas por processos de dominação, acionados pela "lógica da distinção simbólica" que confere um determinado valor ao indivíduo em função da posição que ele ocupa na estrutura social, definida como sistema de posições e de oposições (Bourdieu, 2002). Ao mesmo tempo, os cuidadores podem ser "vítimas estruturais" por sofrerem contradições, incoerências e ambiguidades das instituições (Bourdieu, 2003), especialmente quando se defrontam com uma realidade inaceitável no trabalho, geradora de sofrimento psíquico e de injustiça.

Apesar de grande parte dos resultados ter convergido para a construção de um padrão relativamente homogêneo, apontando para a possível existência de uma discrepância entre a realidade vivenciada por muitos cuidadores e o documento com orientações do Conanda/CNAS, ainda assim não é possível generalizar esses resultados. A escuta e observação desses indivíduos identificou práticas sintonizadas com as normas oficiais, não necessariamente por buscarem cumprir esse manual, talvez pela sensibilidade e comprometimento deles com o significado mais profundo de suas funções. Sempre haverá algum nível de ambiguidade entre teoria e prática, porém, deu-se relevo à singular disparidade entre esses planos, mormente para que sejam envidados esforços procurando minimizar esse hiato. A análise evidenciou que as diferenças individuais tiveram um peso considerável para ampliar ou reduzir essas lacunas. A presença (ou ausência) de certos predicados ou características individuais não deve determinar o curso das atuações profissionais. Há que se estimular o desenvolvimento de práticas profissionais que sejam fruto de um suporte consistente e constante advindo de supervisões, reflexões, estudos de caso e treinamento embasados em situações reais.

\section{Considerações finais}

Concluiu-se que a existência de leis e documentos não assegura o desenvolvimento dos vínculos de socioafetividade, a despeito da existência ou não dos laços biológicos. Para além da questão da adoção, os jovens abrigados precisam vivenciar relacionamentos alicerçados na experiência do agasalhamento emocional. Buscou-se alertar para o fato de que a capacidade desses profissionais de acolher e de se comprometer precisa ser despertada e alimentada por meio da constante supervisão, porquanto os desafios desses relacionamentos são complexos.

É inegável a relevância do documento Orientações técnicas para os serviços de acolhimento para crianças e adolescentes para mapear as ações dos profissionais. Há um consenso de que a equipe multidisciplinar deve se reunir e buscar supervisão, orientação e discussão. Todavia, o desafio não se limita ao fato desse documento ter que ser lido ou relido, mas à sua aplicação. 
Quanto às limitações deste estudo, elas se referiram, basicamente, às dificuldades burocráticas, por parte da rede de abrigos, para que a equipe pudesse aprofundar alguns aspectos da pesquisa. Notadamente, isto ocorreu por mudanças políticas nas gestões do núcleo central, com a troca de profissionais, inviabilizando a continuidade do termo de parceria assinado entre o IPUB/UFRJ e SMAS.

Cabe ressaltar que não se pretendeu extrapolar as dificuldades e opiniões aqui manifestadas para todo o universo dos cuidadores. Porém, elas impulsionam uma reflexão sobre a realidade que outros profissionais possam estar vivendo e, consequentemente, estimular o aprofundamento de investigações futuras. Entre os poucos estudos encontrados sobre o tema, com enfoque na seleção e capacitação de profissionais para este tipo de trabalho, destacam-se as pesquisas que têm demonstrado que esses profissionais enfrentam dificuldades no exercício de suas atividades por falta ou deficiência de capacitação (Alves et al., 2012; Moraes et al., 2012).

Em suma, tais recomendações cumprem a função de lembrar que as pessoas precisam se aproximar, conversar, trocar, escutar e perceber, não só como cuidadores, mas como seres humanos. Há que se restaurar a capacidade 'ultrapassada', que urge ser recuperada: de sentir empatia pelo próximo. Embora despreparados e mal capacitados, muitos profissionais superam as adversidades e acionam recursos próprios para suprir as falhas persistentes do sistema perverso, oferecendo de suas entranhas algo que não tem preço, de inestimável valor: a solidariedade.

\section{Colaboradores}

Elizabeth Espindola Halpern foi responsável pela idealização e elaboração do artigo, atuando como integrante da pesquisa e do referido curso; Ligia Maria Costa Leite foi responsável pelo curso de extensão universitária e pela pesquisa e atuou como orientadora e supervisora dos conteúdos centrais da pesquisa; Mayara Cristina Muniz Bastos Moraes atuou como integrante da pesquisa e do referido curso, bem como dos debates que contribuíram para a elaboração das discussões e conclusões. 
Resumen Se buscó determinar si las percepciones del equipo de profesionales de los abrigos para jóvenes acerca de las dificultades en el trabajo estarían relacionadas con las deficiencias en la selección, capacitación y formación continua. Se realizó una investigación cualitativa en dos abrigos ubicados en Río de Janeiro, Brasil, entre el 2008 y el 2010. Se transcribieron las 47 entrevistas con profesionales de los abrigos y las observaciones de campo en los talleres en grupo. El análisis de los datos identificó puntos críticos que pueden generar violencia, interferir en el manejo de las tareas y agravar los riesgos psicosociales, comprometiendo la salud mental de cuidadores y jóvenes asistidos. Sus relatos se confrontaron con las recomendaciones contenidas en las Orientaciones técnicas para los servicios de acogida de niños y adolescentes, lo que permitió concluir que, si bien este documento permite mapear las acciones de los profesionales y orientar las mejores maneras de realizar la tarea de acoger, éste debe ser asimilado y vivenciado, para reducir la distancia entre lo prescrito y la realidad. Palabras clave cuidador; unidades de acogida; adolescentes; capacitación profesional; selección de personal.

\section{Notas}

${ }^{1}$ Instituto de Psiquiatria, Universidade Federal do Rio de Janeiro, Rio de Janeiro, Brasil. <espindolahalpern@yahoo.com.br>

Correspondência: Rua Botucatu, 460, bloco 4, apartamento 206, Grajaú, CEP 20541-340, Rio de Janeiro, Rio de Janeiro, Brasil.

2 Instituto de Psiquiatria, Universidade Federal do Rio de Janeiro, Rio de Janeiro, Brasil. $<$ ligia.cleite@gmail.com>

3 Instituto de Psiquiatria, Universidade Federal do Rio de Janeiro, Rio de Janeiro, Brasil. <mayacmoraes@gmail.com>

4 A equipe dos abrigos inclui educadores/cuidadores (desenvolvem cuidados com as crianças), coordenador, equipe técnica (assistentes sociais, pedagogos e psicólogos) e de apoio (demais funcionários dos abrigos), enfim, profissionais que atuam nos serviços de acolhimento. Nesta oportunidade, o termo 'cuidadores' poderá ser usado de forma genérica, abarcando os diferentes integrantes da equipe.

5 Este documento regulamenta, em nível nacional, a organização e oferta de Serviços de Acolhimento de Crianças e Adolescentes, no âmbito da política de Assistência Social.

${ }^{6}$ Centros Municipais de Assistência Social Integrada - espaços de proteção social básica (Brasil, 2004). 


\section{Referências}

ALBERTI, Verena. Ouvir contar: textos em história oral. Rio de Janeiro: Editora FGV, 2004.

ALVES, Daniel G. et al. A motivação missionária religiosa dos profissionais das unidades de acolhimento para jovens: problema ou solução?. Revista de Terapia Ocupacional da Universidade de São Paulo, São Paulo, v. 23, n. 2, p. 137-145, 2012.

ARPINI, Dorian M. Violência e exclusão: adolescência em grupos populares. São Paulo: EDUSC, 2003.

BAZON, Marina R.; BIASOLI-ALVES, Zélia M. M. A transformação de monitores em educadores: uma questão de desenvolvimento. Psicologia: Reflexão \& Crítica, Porto Alegre, v. 13, n. 1, p. 199-204, 2000.

BAUMAN, Zygmunt. Modernidade líquida. Rio de Janeiro: Jorge Zahar Ed., 2001.

BOtTeGA, Carla G.; MERLO, Álvaro R. C. Prazer e sofrimento no trabalho dos educadores sociais com adolescentes em situação de rua. Cadernos de Psicologia Social do Trabalho, São Paulo, v. 13, n. 2, p. 259$275,2010$.

BOUDON, Pierre. L'abduction et le camp sémiotique. In: BRUNEL, Gilles. Le tiers communicationnel: communication, légitimation, abduction. Montreal: Editions de L'Harmattan, 1998.

BOURDIEU, Pierre. A produção da crença: contribuição para uma economia dos bens simbólicos. São Paulo, Zouk, 2002.

BOURDIEU, Pierre. A miséria do mundo. Petrópolis: Vozes, 2003.

BRASIL. Lei n. 4.513, de 1 o de dezembro de 1964. Autoriza o Poder Executivo a criar a Fundação Nacional do Bem-Estar do Menor, a ela incorporando o patrimônio e as atribuições do Serviço de Assistência a Meno- res, e dá outras providências. Brasília, DF. Disponível em: <www.planalto.gov.br/ccivil_ 03/leis/1950-1969/L4513.htm>. Acesso em: 18 jun. 2015.

BRASIL. Lei n. 6.697, de 10 de outubro de 1979. Institui o Código de Menores. Brasília, DF. Disponível em: <www.planalto.gov.br/ ccivil_03/leis/1970-1979/L6697.htm >. Acesso em: 18 jun. 2015.

BRASIL. Lei n. 8.069, de 13 de julho de 1990. Dispõe sobre o Estatuto da Criança e do Adolescente (ECA). Brasília, DF. Disponível em: <www.planalto.gov.br/ccivil_03/ Leis/18069.htm>. Acesso em: 18 jun. 2015.

BRASIL. Lei n. 12.010, de 3 de agosto de 2009. Dispõe sobre adoção; altera as leis nos 8.069, de 13 de julho de 1990 - Estatuto da Criança e do Adolescente, 8.560, de 29 de dezembro de 1992; revoga dispositivos da lei n. 10.406, de 10 de janeiro de 2002 - Código Civil, e da Consolidação das Leis do Trabalho CLT, aprovada pelo decreto-lei n. 5.452, de $1^{\circ}$ de maio de 1943; e dá outras providências. Brasília, DF. Disponível em: <www.planalto. gov.br/ccivil_03/_ato2007-2010/2009/lei/ 112010.htm>. Acesso em: 18 jun. 2015.

BRASIL. Decreto n. 24.725, de 18 de outubro de 2004. Dispõe sobre os Cemasis na forma que menciona. Disponível em: <www. leismunicipais.com.br/a/rj/r/rio-de-janeiro/ decreto/2004/2472/24725/decreto-n-247252004-dispoe-sobre-os-cemasis-na-forma-quemenciona.html>. Acesso em: 6 dez. 2013.

BRONFENBRENNER, Urie. A ecologia do desenvolvimento humano. Porto Alegre: Artes Médicas, 1996. (Originalmente publicado em 1979).

CARVALHO, Alysson M. Crianças institucionalizadas e desenvolvimento: possibilidades e desafios. In: LORDELO, Eulina R. CARVALHO, Ana M.; KOLLER, Sílvia H. (org.). Infância brasileira e contextos de desenvolvimento. São Paulo: Casa do Psicólogo, 2002. p. 19-44. 
CASTEL, Robert. As metamorfoses da questão social. Petrópolis: Vozes, 1998.

CONANDA/CNAS (Conselho Nacional dos Direitos da Criança e do Adolescente/Conselho Nacional de Assistência Social). Orientações técnicas para os serviços de acolhimento para crianças e adolescentes. 2008. Disponível em: <www.mprs.mp.br/areas/infancia/ arquivos/conanda_acolhimento.pdf $>$. Acesso em 18 jun. 2015.

COSTA, Jurandir F. O ponto de vista do outro. Rio de Janeiro: Garamond, 2010.

DE ANTONI, Clarissa; KOLLER, Sílvia H. O psicólogo ecológico no contexto institucional: uma experiência com meninas vítimas de violência. Psicologia: Ciência e Profissão, Brasília, v. 21, n. 1, p. 14-29, 2001.

DELL'AGLIO, Debora D. O processo de coping, institucionalização e eventos de vida em crianças e adolescentes. 2000. 119 fls. Tese (Doutorado em Psicologia do Desenvolvimento) Programa de Pós-graduação em Psicologia do Desenvolvimento, Universidade Federal do Rio Grande do Sul, Porto Alegre, 2000.

DEJOURS, Christophe. Conferências brasileiras: identidade, reconhecimento e transgressão no trabalho. São Paulo: Fundap, FGV, 1999.

DEJOURS, Christophe. O fator humano. Rio de Janeiro: Editora FGV, 2005.

DELGADO, Paulo. A perspectiva ecológica: referências para a preparação e a cessação da estadia em acolhimento familiar de crianças. Psicologia: Reflexão e Crítica, Brasília, v. 25, n. 2, p. 359-367, 2012

FOUCAULT, Michel. Microfísica do poder. Rio de Janeiro: Edições Graal, 1979.

FOUCAULT, Michel. Vigiar e punir: nascimento da prisão. 34. ed. Petrópolis: Vozes, 2007. (Originalmente publicado em 1975).
GOFFMAN, Erving. Manicômios, prisões e conventos. São Paulo: Editora Perspectiva, 1992. (Originalmente publicado em 1961).

GROLEAU, Danielle; YOUNG, Allan; KIRMAYER, Laurence J. The McGill Illness Narrative Interview (MINI): an interview schedule to elicit meanings and modes of reasoning related to illness experience. Transcultural Psychiatry, Montreal, v. 43, n. 4, p. 671-691, 2006.

LEITE, Ligia M. C. Meninos de rua: a infância excluída no Brasil. 4. ed. São Paulo: Saraiva \& Atual, 2001.

LEITE, Ligia M. C. et al. Violência, juventude e saúde mental. Universidade Federal do Rio de Janeiro - Instituto de Psiquiatria UFRJ/IPUB, Projeto de Pesquisa, 2008.

LEITE, Ligia M. C. et al. Violência, juventude e saúde mental. Universidade Federal do Rio de Janeiro, Instituto de Psiquiatria UFRJ/IPUB, Relatório final não publicado, 2011.

MARTINS, Edna; SZYMANSKI, Heloisa. Brincando de casinha: significado de família para crianças institucionalizadas. Estudos de Psicologia, Natal, v. 9, n. 1, p. 177-187, 2004.

MINAYO, Maria C. S. O desafio do conhecimento: pesquisa qualitativa em saúde. 9. ed. São Paulo: Hucitec, 2006.

MINAYO, Maria C. S; DESLANDES, Suely F.; GOMES, Romeu. Pesquisa social: teoria, método e criatividade. 26. ed. Petrópolis: Vozes, 2007. MORAES, Mayara C. M. B. et al. Saúde mental de cuidadores de abrigos para adolescentes com transtornos psiquiátricos ou neurológicos. Trabalho, Educação e Saúde, Rio de Janeiro, v. 10, n. 3, nov. p. 507-525, 2012.

PASIAN, Sonia R.; JACQUEMIN, André. O autorretrato em crianças institucionalizadas. Paidéia, Ribeirão Preto, v. 9, n. 17, p. 50-60, 1999. 
PITTA, Ana M. F. (Org). Reabilitação psicossocial no Brasil. São Paulo: Hucitec, 1996.

RIZZINI, Irene; RIZZINI, Irma. A institucionalização de crianças no Brasil. Rio de Janeiro: Editora PUC-Rio, 2004.

ROSA, Edinete M. et. al. Contextos ecológicos em uma instituição de acolhimento para crianças. Estudos de Psicologia, Natal, v. 15, n. 3, p. 233-241, 2010.

ROSA, Edinete M. et al. O processo de desligamento de adolescentes em acolhimento institucional. Estudos de Psicologia, Natal, v. 17, n. 3, p. 361-368, 2012.

SARACENO, Benedetto. Libertando identidades: da reabilitação psicossocial à cidadania possível. Belo Horizonte/Rio de Janeiro: Te Corá/Instituto Franco Basaglia, 1999.

SENNET, Richard. A corrosão do caráter: consequências pessoais do trabalho no novo capitalismo. Rio de Janeiro: Record, 2003.
SILVA, Enid R. A. O direito à convivência familiar e comunitária: os abrigos para crianças e adolescentes no Brasil. Brasília: IPEA/ Conanda, 2004.

SIQUEIRA, Aline C.; DELL'AGLIO, Débora D. O impacto da institucionalização na infância e na adolescência: uma revisão de literatura. Psicologia \& Sociedade, Porto Alegre, v. 18, n. 1, p. 71-80, 2006.

SOUSA, Walter G. A Nova Lei da Adoção e seus efeitos. 30 ago. 2011. Disponível em: <www.tjdft.jus.br/institucional/imprensa/ artigos/2011/a-nova-lei-da-adocao-e-seusefeitos-walter-gomes-de-sousa > . Acesso em: 8 dez. 2013.

YUNES, Maria A. M.; MIRANDA, Angela T.; CUELLO, Sandra E. S. Um olhar ecológico para os riscos e as oportunidades de desenvolvimento de crianças e adolescentes institucionalizados. In: KOLLER, Silvia H. (org.), Ecologia do desenvolvimento humano: pesquisa e intervenções no Brasil. São Paulo: Casa do Psicólogo, 2004. p. 197-218.

Recebido em 09/08/2013

Aprovado em 11/03/2014 